\title{
AlCANCES DE La ACCIÓN DE AMParo ANTE EL JUEZ DE GARANTÍA*
}

\section{RODRIgo Ríos ÁlVAREZ**}

Resumen: A diferencia de lo que hacía el antiguo Código de Procedimiento Penal, que contenía una regulación detallada en torno al procedimiento del recurso de amparo, el actual Código Procesal Penal omite cualquier pronunciamiento al respecto, consagrando una norma única referida a esta materia, y que es la "acción de amparo ante el Juez de Garantía”. Desde que dicha norma se encuentra en aplicación, han surgido una serie de problemas interpretativos en torno al alcance de esta acción de rango legal, y que dicen relación con las finalidades que se pueden perseguir, así como qué tribunal será el competente para conocer de la misma. El presente trabajo realiza un resumen de dichos problemas, a través de revisión crítica del estado actual de discusión, buscando ampliar los márgenes que hoy en día se le reconocen como ámbito de aplicación a esta acción ante el Juez de Garantía.

PALABRAS CLAVE: Acción de amparo; Juzgado de garantía; Artículo 95 del Código Procesal Penal

\section{SCOPES OF THE WRIT OF PROTECTION BEFORE THE JUDGE OF GUARANTEE}

\begin{abstract}
Unlike the former Code of Criminal Procedure, which contained a detailed regulation regarding the procedure for the writ of protection, the current Code of Criminal Procedure omits any pronouncement in this regard, enshrining a single rule related to this matter, which is the writ of protection before the Judge of Guarantee. Since this standard has been applied, a number of interpretative problems have arisen as to the scope
\end{abstract}

Fecha de recepción: 6 de diciembre de 2016.

Fecha de aceptación: 14 de julio de 2017.

** Profesor de Derecho Procesal Penal y Litigación Oral, Facultad de Derecho, Universidad Finis Terrae (Chile). Magíster en Derecho con Mención en Derecho Público y Abogado de la Universidad de Chile. Correo electrónico: rrios@uft.cl 
of this legal action. For example, those linked to the purposes that may be pursued, as well as the potential court that will be competent to hear about it. The present work makes a tour of these problems, through a critical review of the current state of discussion, seeking to expand the margins that today are recognized as the area of application of this action.

KEY WORDS: Writ of protection; Court of Guarantee; Article 95 of Criminal Procedure Code

Sumario: Introducción. 1) Alcance del amparo legal. 2) Tribunal competente. 3) Procedencia del amparo legal respecto de resoluciones judiciales. 4) Procedencia del amparo legal ante resoluciones dictadas por jueces con competencia diversa a materia penal. 5) Procedencia del amparo legal ante privaciones de libertad que emanen de autoridades que no ejerzan jurisdicción. Conclusiones. Bibliografia.

\section{INTRODUCCIÓN}

El artículo 95 del Código Procesal Penal regula el "Amparo ante el Juez de Garantía". En lo relativo al alcance de esta acción de amparo legal, la norma en comento contempla en su inciso primero el derecho que tiene toda persona que se encuentre privada de libertad a efectos de ser conducida, sin demora, ante un Juez de Garantía. Establece el legislador que el objeto de esta petición formulada por la persona privada de libertad, puede ser:

1.- Que el Juez de Garantía examine la legalidad de la privación de libertad, y

2.- Para que el Juez de Garantía examine las condiciones en que se encontrare la persona privada de libertad, constituyéndose si fuere necesario, en el lugar donde ella se estuviese.

En el contexto indicado, el Juez de Garantía podrá ordenar la libertad del afectado o bien adoptar las medidas que fueren procedentes de acuerdo al caso en concreto.

Luego, en su inciso segundo agrega, que el abogado de la persona privada de libertad, sus parientes o cualquier persona en su nombre, podrán siempre ocurrir ante el juez que conociere del caso o aquel del lugar donde aquella se encontrare, con la finalidad de solicitar que dicha persona sea conducida a presencia del juez y se ejerzan las facultades que contempla el inciso primero, esto es, realizar un examen de legalidad de la privación de libertad y que examine las condiciones en las que se encontrare dicha persona, con la posibilidad de que el juez se constituye en dicho lugar para satisfacer estas finalidades. 
Finalmente, y no por ello menos importante, se encuentra el inciso tercero que nos señala que, si la privación de libertad hubiere sido ordenada por resolución judicial, su legalidad solo podrá impugnarse por los medios procesales que correspondan ante el tribunal que la hubiere dictado, sin perjuicio del "recurso de amparo" constitucional del artículo 21 de la Constitución Política de la República.

Así, tenemos que el Amparo ante el Juez de Garantía constituye una regulación novedosa respecto de nuestra historia procesal penal, por cuanto en el antiguo Código de Procedimiento Penal, en sus artículos 306 y siguientes, se regulaba el procedimiento del "recurso de amparo" del artículo 21 de la Constitución Política de la República ${ }^{1}$. Luego, con la entrada en vigor del nuevo Código Procesal Penal el legislador optó por omitir dicha regulación, incorporando únicamente la norma del artículo 95 en comento ${ }^{2}$.

\section{1) ALCANCE DEL AMPARO LEGAL}

Como primera constatación, podemos señalar que en la actual regulación el Código Procesal Penal solo consagra en materia de acción de amparo la norma del artículo 95, diferenciándola desde ya con la acción

1 El Título V del Libro II del Código de Procedimiento Penal se titulaba "Del procedimiento de amparo", abarcando de los artículos 306 a 317 bis, ambos inclusive, diversos aspectos vinculados con la tramitación de la acción de amparo del artículo 21 de la Constitución Política de la República. Dentro de las normas de mayor incidencia en términos de tramitación, podemos destacar el artículo 308, que disponía que el recurso debía ser fallado, por regla general, en el plazo de veinticuatro horas, mismo plazo que se contemplaba para la interposición del recurso de apelación en contra de la resolución dictada por la Corte de Apelaciones respectiva, según lo dispuesto en el artículo 316.

2 Véase sobre este punto, la discusión surgida en la tramitación parlamentaria, y la necesidad de contar con una ley especial que regule de forma integral las acciones constitucionales, Londoño, Fernando. et al. (2003) Reforma procesal Penal. Génesis, historia sistematizada y concordancias. Código Procesal Penal Libro I, Tomo I. Santiago: Editorial Jurídica de Chile, 802 pp., p. 506 y ss.; Interesante resulta en este debate la intervención que realizó la Ministra de Justicia de la época, Sra. Alvear, quien ante el emplazamiento de mantener o no la vigencia de las normas procedimentales del recurso de amparo contenidas en el antiguo Código de procedimiento, y la necesidad de dictar una ley especial que regulase las acciones constitucionales, sostuvo "[...] ratificando la voluntad del Ministerio de proponer un proyecto de ley que regule las acciones constitucionales en su conjunto [...] Sin embargo, desde el punto de vista de la priorización de los proyectos, resulta razonable la posibilidad de la solución transitoria respecto del amparo, porque el despacho de ese otro proyecto general podría demorar más allá de la entrada en vigencia de la reforma procesal penal [...] sin perjuicio de lo cual se presentaría a la brevedad el proyecto de ley de procedimiento de las acciones constitucionales". 1er. Informe Comisión Constitución, Legislación, Justicia y Reglamento; Discusión General; 13.2. Eliminación del recurso de amparo del Código. LonDOÑO (2003) 508. 
del artículo 21 de la Constitución Política de la República ${ }^{3}$. En este sentido, la acción de amparo del artículo 95 del Código Procesal Penal está circunscrita exclusivamente a hipótesis de privación de libertad, por lo que cualquier otra situación de menor intensidad, como podrían ser las amenazas, restricciones o perturbaciones a la libertad o sus atributos, indefectiblemente quedará fuera del ámbito de aplicación de esta acción de rango legal. Dentro de estos casos que quedan fuera del alcance de esta norma, podemos citar a modo ejemplar las medidas cautelares personales del artículo 155 del Código Procesal Penal (sujeción a la vigilancia de una persona o institución, la obligación de presentarse periódicamente ante el juez o ante la autoridad que él designare, la prohibición de salir del país, prohibiciones de acercamiento a lugares o personas determinadas, etcétera $)^{4}$, casos de apercibimientos aparejados a citaciones $(v$. gr. citaciones formuladas por el Ministerio Público, bajo apercibimiento de utilizar la fuerza pública) $)^{5}$, entre otros. Todos estos casos que se sitúan bajo la intensidad propia de la privación de libertad, quedan excluidos del ámbito de aplicación del amparo legal del artículo 95, estando siempre a resguardo de dichas hipótesis la acción de amparo del artículo 21 de la Constitución Política de la República que sí abarca situaciones de amenazas o

3 Para un estudio acabado de los alcances del habeas corpus constitucional en nuestro país, véase, Tavolari, Raúl (1995) Habeas Corpus. Recurso de amparo. Santiago: Editorial Jurídica de Chile, 207 pp., y Caffarena DE Jiles, Elena (1975) El recurso de amparo frente a los regimenes de emergencia. Santiago: Impresores San Francisco, 279 pp. De manera más reciente, puede consultarse además el trabajo de Pérez, Alejandro (2008) Generalidades del habeas corpus constitucional chileno. Historia, doctrina y jurisprudencia. Santiago: Librotecnia, 247 pp.

4 Podría plantearse una duda en torno a la medida cautelar personal contenida en la letra a) del artículo 155 del Código Procesal Penal, que dispone "la privación de libertad, total o parcial, en su casa o en la que el propio imputado señalare, si aquella se encontrare fuera de la ciudad asiento del tribunal", por cuanto se estaría derechamente en presencia de una privación de libertad, mas no ante una amenaza o perturbación, por lo que en estricto rigor sería -opinión que compartimos- potencialmente una hipótesis subsumible en los márgenes del artículo 95 del Código Procesal Penal. Abona esta conclusión, el hecho de que el propio legislador le ha reconocido tal carácter -de medida que priva de libertad en términos análogos a una prisión preventiva- en el inciso segundo del artículo 348 del Código Procesal Penal, al disponer que "la sentencia que condenare a una pena temporal deberá expresar con toda precisión el día desde el cual empezará esta a contarse y fijará el tiempo de detención, prisión preventiva y privación de libertad impuesta en conformidad a la letra a) del artículo 155 que deberá servir de abono para su cumplimiento. Para estos efectos, se abonará a la pena impuesta un día por cada día completo, o fracción igual o superior a doce horas, de dichas medidas cautelares que hubiere cumplido el condenado".

5 Principalmente referido al apercibimiento que contiene el inciso segundo del artículo 33 del Código Procesal Penal, que en lo medular establece que "se hará saber a los citados el tribunal ante el cual debieren comparecer, su domicilio, la fecha y hora de la audiencia, la identificación del proceso de que se tratare y el motivo de su comparecencia. Al mismo tiempo se les advertirá que la no comparecencia injustificada dará lugar a que sean conducidos por medio de la fuerza pública, que quedarán obligados al pago de las costas que causaren y que pueden imponérseles sanciones $[\ldots] "$. 
perturbaciones $^{6}$ a la libertad personal y seguridad individual ${ }^{7}$, además de todas aquellas que constituyen privaciones de libertad ${ }^{8}$.

Así las cosas, podemos constatar que esta "acción de amparo ante el Juez de Garantía" es un derecho reconocido a toda persona que se encuentre actualmente privada de libertad, para solicitar a dicho juez que examine la legalidad de ese estado de privación, y a su vez, pueda revisar las condiciones bajo las cuales se encontrase dicha persona. Este es un punto de mucha relevancia al momento de determinar el alcance de esta acción de amparo, por cuanto se tiende a reducir la finalidad de esta acción solo al test de legalidad que pueda realizar el Juez de Garantía, olvidando que en todo caso dicho juez siempre podrá, además, examinar las condiciones en las cuales se encuentra la persona privada de libertad, estando facultado, en uno u otro caso, a ordenar la libertad del afectado o bien adoptar la o las medidas que estime pertinentes para salvaguardar los derechos de la persona privada de libertad?

Entonces, como una primera aclaración, debemos tener siempre presente el hecho de que las finalidades de esta acción de amparo van mucho más allá de un examen de legalidad de la privación de libertad propiamente tal, sino que, por ejemplo, tal como dispone la norma en comento, la revisión de las condiciones bajo las cuales se encuentra la persona priva-

6 Es lo que en doctrina se ha denominado recurso de amparo preventivo (teniendo como correlato al amparo correctivo que refiere a hipótesis de privación de libertad), entendiendo por tal "aquel que persigue poner término o modificar toda otra acción u omisión arbitraria o ilegal, que sin haberse llegado a constituir en un arraigo, arresto, detención o prisión, importe una perturbación o amenaza a su derecho a la libertad personal y seguridad individual", Mosquera, Mario y Maturana, Cristián (2013) Los Recursos Procesales. Santiago: Editorial Jurídica de Chile, 619 pp., p. 438. En el mismo sentido, Tavolari, (1995) 124. Nogueira, Humberto (2013) Derechos Fundamentales y garantías constitucionales, 4a edición, Tomo 1. Santiago: Librotecnia, 994 pp., p. 404. Flores, René (2011) Amparo, habeas corpus y habeas data, 3a edición. Buenos Aires: Editorial B de F, 327 pp., p. 41; Henríquez, Miriam (2014) Habeas corpus. En Silva. M. y Henríquez, M. (coords.): Acciones protectoras de derechos fundamentales. Santiago: Thomson Reuters, pp. 5-29, p. 12.

7 El artículo 21 de la Constitución Política de la República en lo pertinente dispone que "todo individuo que se hallare arrestado, detenido o preso con infracción de lo dispuesto en la Constitución Política de la República o en las leyes, podrá ocurrir por sí, o por cualquiera a su nombre, a la magistratura que señale la ley, a fin de que esta ordene se guarden las formalidades legales y adopte de inmediato las providencias que juzgue necesarias para restablecer el imperio del derecho y asegurar la debida protección del afectado. [...] El mismo recurso, y en igual forma, podrá ser deducido en favor de toda persona que ilegalmente sufra cualquiera otra privación, perturbación o amenaza en su derecho a la libertad personal y seguridad individual [...]".

8 En este sentido, ambas acciones de amparo (legal y constitucional) tendrían competencia para subsumir hipótesis de privaciones de libertad, más no así de amenazas, perturbaciones y restricciones a dicha garantía, en que el artículo 95 se torna inaplicable.

9 Fernández, Miguel Ángel (2006) La nueva justicia penal frente a la Constitución. Santiago: LegalPublishing, 334 pp., pp. 42 y 43. 
da de libertad, constituye una finalidad que per se justifica el ejercicio de esta acción ante el Juez de Garantía ${ }^{10}$.

\section{2) Tribunal COMPETENTE}

Debemos tener en vista, y en concordancia con el alcance del inciso segundo del artículo 95, que tanto el abogado de la persona privada de libertad, sus parientes o cualquier persona en su nombre ${ }^{11}$ podrán ejercer esta acción ante el juez que conociere del caso o aquel del lugar donde aquella se encontrare. Todo con la finalidad de que la persona privada de libertad sea conducida a presencia de dicho juez, y que este pueda ejercer las facultades previstas en el inciso primero que acabamos de mencionar: examen de legalidad de la privación de libertad y de condiciones bajo las que se encuentra la persona. El legislador dejó claramente establecido que se puede ocurrir ante el juez que conociere del caso o aquel del lugar donde aquella se encontrare ${ }^{12}$. Esta manifestación legislativa debemos entenderla contextualizada con las normas que regulan la competencia

10 Como señala Nieva, al analizar el habeas corpus, "la finalidad es simplemente la comparecencia del detenido ante el juez, sin más, para que decida sobre su situación personal de privación de libertad. Por extensión también se suele dedicar el juez a analizar las condiciones de la detención, en averiguación de malos tratos”, Nieva, Jordi (2012) Fundamentos de Derecho Procesal Penal. Buenos Aires: Editorial B de F, 338 pp., p. 180.

11 En el análisis que rodea al habeas corpus del artículo 21 de la Constitución, sobre este punto se suele hablar de que estamos en presencia de una acción popular, tal como señala Núñez, "el precepto del artículo 21 de la Carta Fundamental otorga legitimación para interponer el amparo tanto al que se hallare arrestado, detenido o preso, amenazado o perturbado en su libertad o seguridad individual, en su condición de agraviado, como a cualquiera persona en su nombre, ya que la ley confiere acción popular para que la ejerza quienquiera del pueblo, siempre que ostente capacidad para parecer en juicio”, NúNEEZ, Juan Cristóbal (2003) Tratado del proceso penal y del juicio oral. Tomo II. Santiago: Editorial Jurídica de Chile, 581 pp., p. 396. En una posición contraria, véase TAvolari (1995) 111 y 112. En lo medular, Tavolari descarta que estemos ante una acción de estas características, por cuanto “[...] caracteriza a la acción popular no solo la posibilidad de ejercicio por cualquier sujeto, sino básicamente el que la titularidad sustancial es compartida, por tener cada cual personal y directo interés en los resultados favorables que se persiguen. Estas condiciones no se dan en el habeas corpus, desde que el favorecido con un resultado favorable es, exclusivamente el sujeto por quien se recurre, quedando así, de relieve, la circunstancia de tratarse, meramente, de una amplísima posibilidad de ejercicio de la acción, de características semejantes a una casi ilimitada agencia oficiosa”. Tavolari (1995) 112. Tesis esta última a la cual nosotros adherimos.

12 Respecto de la acción constitucional de amparo del artículo 21, en términos de tribunal competente se habla de la "Corte de Apelaciones respectiva", generándose debate en torno a la determinación de dicha frase, y la consecuencial determinación de cuál o cuáles de todas las Cortes de Apelaciones del país sería(n) competente(s) para conocer de una acción interpuesta bajo esa normativa. Véase Caffarena de Jiles (1957) 162 y ss. Tavolari (1995) 129 y ss. Nogueira (2013) 410 y 411 . Henríquez (2014) 21 y ss. Mosquera y Maturana (2013) 447 y ss. En Derecho comparado también ha surgido debate en torno a este punto, especialmente en España, véase Gude, Ana (2008) El habeas corpus en España. Valencia: 
material y territorial de los tribunales en materia penal. Así las cosas, pacífico resulta entender que si se trata de un procedimiento en el cual es competente un determinado Juzgado de Garantía ${ }^{13}$, potencialmente este tribunal será uno de los dos ante los cuales podrá ocurrir el abogado, los parientes o cualquier persona a nombre del privado de libertad, por cuanto la otra alternativa estará siempre dada por aquel Juzgado de Garantía correspondiente al territorio donde la persona se encontrare efectivamente privada de libertad, en caso que se trate de territorios diversos.

Existirá una duda en la etapa de juicio oral, por cuanto en esta etapa del procedimiento ordinario es competente, de acuerdo a las reglas contenidas en el Código Procesal Penal ${ }^{14}$ y en el Código Orgánico de Tribunales ${ }^{15}$, el Tribunal de Juicio Oral en lo Penal. Señala en este punto el Fiscal Nacional en su Oficio $N^{\circ}$ 60/2014, que "este amparo especial puede intentarse no solo ante el juez de garantía sino que, excepcionalmente, ante el tribunal del juicio oral, y tiene por objeto únicamente la conducción del detenido ante el juez para verificar las condiciones y legalidad de su detención y para la adopción de medidas para subsanar los defectos de su detención"16. A nivel doctrinario, Núñez sostiene esta opinión al señalar que "en la actualidad, en nuestro Derecho existen dos clases de acciones de habeas corpus: una de carácter especial, establecida por la ley en el artículo 95 del C.P.P. para proteger, a través de la acción promovida ante el correspondiente juez de garantía o tribunal oral en lo penal que conociere del caso [...]"17. Esta postura se basa en el hecho de que el Juzgado de Garantía una vez que remite el auto de apertura de juicio oral al Tribunal de Juicio Oral en lo Penal respectivo ${ }^{18}$, deja de ser competente, y pasa a asumir tal competencia el Tribunal de Juicio Oral en lo Penal hasta que la sentencia definitiva dictada en el juicio oral ante él desarrollado ${ }^{19}$ se encuentre firme o

Tirant lo Blanch, 206 pp., p. 74 y ss., y DE DiEgo, Luis (2011) Habeas corpus frente a detenciones ilegales, 2a edición. España: Bosch, 240 pp., p.127 y ss. De acuerdo a las reglas contenidas en el artículo 70 del Código Procesal Penal.

14 Por ejemplo, artículo 281 y siguientes del Código Procesal Penal, relativos a la etapa de juicio oral.

15 Artículo 17 y ss., insertos en el Título I, del Código Orgánico de Tribunales, referido al Poder Judicial y a la Administración de Justicia en General.

16 Ministerio Público. Fiscalía Nacional (2014) Oficio $\mathrm{N}^{\circ}$ 60, Instrucción general que imparte criterios de actuación aplicables a la etapa de investigación en el proceso penal. Santiago: inédito, 47. Este Oficio mantiene la misma línea de su predecesor, esto es, el Oficio $\mathrm{N}^{\circ}$ 133/2010, de 31 de marzo de 2010.

17 NúŃEZ, J.C. (2003) 385.

18 El artículo 281 Código Procesal Penal, dispone que "[...] el juez de garantía hará llegar el auto de apertura del juicio oral al tribunal competente, dentro de las cuarenta y ocho horas siguientes al momento en que quedare firme. También pondrá a disposición del tribunal de juicio oral en lo penal las personas sometidas a prisión preventiva o a otras medidas cautelares personales".

19 Con relación a esta tercera etapa del proceso penal, o etapa de juicio oral, esta hipótesis de clausura de competencia (referida a la dictación de una sentencia definitiva y su conse- 
ejecutoriada ${ }^{20}$. Si bien la postura en comento no se explaya en mayores fundamentos en torno a esta situación, entendemos que el argumento de fondo se entronca en estos aspectos de competencia.

A nuestro criterio, no se puede soslayar el hecho de que desde que el Tribunal de Juicio Oral en lo Penal recepciona el auto de apertura de juicio oral de parte del Juzgado de Garantía respectivo, este último deja de ser competente para seguir conociendo del caso en concreto en las actuaciones consecutivas que permiten el desarrollo del procedimiento ordinario, pero ello no es óbice para sostener que respecto del amparo de rango legal el Juzgado de Garantía siempre será competente materialmente para conocer de dicha acción, por expreso mandato de las normas en juego, tanto del Código Procesal Penal (artículo 95) como del Código Orgánico de Tribunales (artículo 14), donde se le asigna la función de asegurar los derechos del imputado y de los demás intervinientes en el proceso penal.

Incluso si prescindiéramos del argumento anterior, perfectamente podríamos llegar a la misma conclusión de descartar la competencia del Tribunal de Juicio Oral en lo Penal, en la medida que dotemos de sentido el tenor del inciso segundo del artículo 95, en cuanto utiliza la conjunción "o" para diferenciar entre dos potenciales Juzgados de Garantía competentes para conocer de este amparo legal. Así, dicho inciso hace alusión al juez que conociere del caso o aquel del lugar donde la persona privada de libertad se encontrare. Para mantener una interpretación armónica entre las normas de competencia del Código Procesal Penal y las contempladas en el Código Orgánico de Tribunales, y encontrándonos en la etapa de juicio oral ante un Tribunal de Juicio Oral en lo Penal, si se diese una hipótesis que ameritase la interposición de un amparo legal, el tribunal competente será el Juzgado de Garantía del lugar donde se encontrase privada de libertad la persona. Por ello el legislador habría empleado la conjunción "o", para efectos de permitir ocurrir siempre ante un Juzgado de Garantía, ratificando con ello la competencia material de estos tribunales, y que no es otra que "asegurar los derechos del imputado y de los demás intervinientes en el proceso penal, de acuerdo con la ley procesal penal",

cuencial estado de ejecutoriada) es la regla general, por cuanto perfectamente podría surgir alguna situación que ameritase la dictación, por ejemplo, de un sobreseimiento definitivo, que evidentemente también pondría término a esta etapa procesal. En una opinión diversa, Horvitz, María Inés y López, Julián (2003) Derecho Procesal Penal Chileno, Tomo I. Santiago: Editorial Jurídica de Chile, 638 pp., p. 208.

Si se trata de una sentencia definitiva condenatoria, la ejecución de dicha sentencia queda entregada al Juzgado de Garantía respectivo, con lo cual este retoma su competencia para dicha finalidad, tal como lo disponen los artículos 466 y siguientes del Código Procesal Penal. 
tal como dispone el artículo 14 letra a) del Código Orgánico de Tribunales ${ }^{21}$.

Ya sea con una u otra explicación, es pacífico colegir que con la dictación del auto de apertura de juicio oral el Juzgado de Garantía no pierde competencia material para conocer de determinados asuntos, especialmente vinculados con el resguardo de garantías fundamentales. Esta conclusión no constituye una excepción al desasimiento del tribunal que emana de la dictación del auto de apertura de juicio oral, por cuanto el Juzgado de Garantía materialmente siempre será el tribunal encargado de salvaguardar los derechos del imputado y demás intervinientes, independientemente de la etapa procesal en la cual nos encontremos. Una conclusión similar puede arribarse en el análisis de la cautela de garantías del artículo 10 del Código Procesal Penal, por cuanto se trata de una institución, que al igual que el amparo del artículo 95, dice relación con aspectos propios de competencia material de los Juzgados de Garantía 22 .

21 En este sentido, Núñez, Raúl (2016) Código Procesal Penal. Códigos Profesionales 2016. Santiago: Thomson Reuters-La Ley, 616 pp., p. 106. Quien señala que "es esta una proyección de esta función respecto de las garantías no judiciales del imputado". CHAHUÁn, Sabas (2012) Manual del Nuevo Procedimiento Penal, Séptima edición. Santiago: Thomson Reuters, 464 pp., p. 130. Una conclusión similar debe arribarse en el contexto de un procedimiento de extradición activa, de acuerdo a las reglas contenidas en los artículos 431 y siguientes del Código Procesal Penal, cuando se trate de un acusado que se haya restado del desarrollo del juicio oral dirigido en su contra, y que se encuentre en el extranjero. Se trata de una hipótesis similar, por cuanto el tribunal competente en esta etapa del proceso es el Tribunal de Juicio Oral en lo Penal, y para poder obtener la extradición de dicho acusado, que permita en definitiva su juzgamiento en Chile, deberá generarse la tramitación de una solicitud de extradición activa ante el juez de garantía respectivo, y que no es otro, que aquel que fue competente previo al inicio de la etapa de juicio oral.

22 En nuestra doctrina existe dos posiciones que refieren a la oportunidad en la cual debe tener lugar la discusión de cautela de garantías. La primera, basada en el inciso primero del artículo 10 , señala que puede tener lugar en cualquier etapa del procedimiento. Defienden esta postura, Durán, Rodrigo (2011) Medidas cautelares personales en el proceso penal, $3^{a}$ edición. Santiago: Librotecnia, 298 pp., p. 85; Cerda, Rodrigo et al. (2003) El Código Procesal Penal. Comentarios, concordancias y jurisprudencia. Santiago: Librotecnia, 539 pp., p. 27. Por su parte, la segunda postura sostiene que la cautela de garantías solo puede tener lugar en las etapas de investigación e intermedia, "antes de que la causa llegue a conocimiento del tribunal de juicio oral en lo penal, ya que de lo contrario se producirían graves trastornos en la tramitación de las causas en la etapa de juicio oral", NúNEZ, R. (2016) 45. Existen además argumentos en la historia de tramitación legislativa que vienen a consolidar esta segunda conclusión. En el mismo sentido, Maturana, Cristián y Montero, Raúl (2012) Derecho Procesal Penal, Tomo I, Segunda edición. Santiago: Editorial Jurídica de Chile, 594 pp., p. 169; CHAhuán (2012) 46. CAstro, Javier (2008) Introducción al Derecho Procesal Penal Chileno, $2^{\mathrm{a}}$ edición. Santiago: LegalPublishing, 605 pp., p. 84; Horvitz y López (2003) 101; Salas, Jaime (2015) Problemas del proceso penal. Investigación, etapa intermedia y procedimientos especiales, $2^{2}$ edición. Santiago: Librotecnia, 450 pp., pp., 66-67, quien agrega que de producirse durante el desarrollo del juicio oral alguna situación que pudiera subsumirse en el inciso segundo del artículo 10, esta deberá resolverse de acuerdo a lo dispuesto en el artículo 283 del Código Procesal Penal, mediante la suspensión de la audiencia o del juicio oral. Nosotros adherimos a esta segunda postura, por cuanto el legislador realiza una atribución de competencia expresa al Juzgado de Garantía (sumado al tenor literal del artículo 69 del Código Procesal Penal), además 
Sin duda que esta problemática no se va a plantear en la medida en que estemos en la etapa de investigación o en la etapa intermedia o de preparación de juicio oral, por cuanto en ambas es competente el Juzgado de Garantía, no teniendo participación alguna el Tribunal de Juicio Oral en lo Penal.

Ahora bien, se podría contraargumentar señalando que la intención del legislador al establecer la opción de accionar ante el juez que conociere del caso o aquel del lugar donde la persona privada de libertad se encontrare, era precisamente permitir en la primera hipótesis, interponer la acción de amparo legal ante un Tribunal de Juicio Oral en lo Penal, cada vez que nos encontremos en la etapa de juicio oral, por cuanto este será el tribunal que esté conociendo del caso, y no el Juzgado de Garantía. Ante ello se puede replicar que el legislador ha empleado literalmente la referencia a Juez de Garantía en el enunciado e inciso primero del artículo 95, no haciendo referencia alguna al Tribunal de Juicio Oral en lo Penal. Luego, en el inciso segundo del artículo 95 ha empleado la voz "juez", esto es "juez que conociere del caso", y el artículo 69 del Código Procesal Penal $^{23}$ que se refiere a las denominaciones de los tribunales establece que "salvo que se disponga expresamente lo contrario, cada vez que en este Código se hiciere referencia al juez, se entenderá que se alude al juez de garantía; si la referencia fuere al tribunal de juicio oral en lo penal, deberá entenderse hecha al tribunal colegiado encargado de conocer el juicio mencionado". Por lo tanto, teniendo presente dicha norma, la referencia del artículo 95 es a todo evento al Juez de Garantía.

En otras palabras, de acuerdo a la naturaleza propia de la acción de amparo legal, debemos entender que el Juzgado de Garantía será siempre competente para pronunciarse ante una acción interpuesta en este contexto, básicamente por criterios materiales de competencia. Luego, en base a la distinción que realiza el inciso segundo del artículo 95, puede concluirse con el mismo énfasis que siempre será competente el Juez de Garantía del territorio donde se encontrare la persona privada de libertad, mas no así aquel Juzgado de Garantía que haya conocido del caso hasta la dictación y remisión del auto de apertura de juicio oral al Tribunal de Juicio Oral en lo Penal respectivo, momento en el cual este último tribunal será el que se encontrará "conociendo del caso", pero que carecerá de compe-

de coincidir con la solución que debe darse a una situación de cautela durante el desarrollo mismo de la audiencia de juicio oral. Especificando que respecto de todas aquellas hipótesis que requieran ser cauteladas durante la tercera etapa del proceso, y que no se enmarquen en el desarrollo mismo de la audiencia de juicio oral, deberán ser conocidas y resultas siempre por el Juzgado de Garantía, quien es el tribunal materialmente competente -al igual que con el amparo del artículo 95- para conocer de estas discusiones.

23 Para una revisión de la historia del establecimiento de esta norma, Londoño (2003) 333335; Pfeffer, Emilio (2010) Código Procesal Penal. Anotado y concordado. 3a Edición. Santiago: Editorial Jurídica de Chile, 693 pp., p. 85. 
tencia material para conocer del amparo legal del artículo 95, tanto por el propio tenor del artículo 95, así como por el contenido de los artículos 14 y 18 del Código Orgánico de Tribunales.

\section{3) Procedencia del amparo legal ReSPeCto de Resoluciones JUDICIALES}

El inciso tercero del artículo 95 del Código Procesal Penal apunta a que la legalidad de toda privación de libertad que hubiere sido ordenada por resolución judicial solo podrá impugnarse por los medios procesales que correspondan ante el tribunal que la hubiere dictado, sin perjuicio de lo establecido en el artículo 21 de la Constitución Política de la República.

Este inciso establece una doble vía ${ }^{24}$ para efectos de poder impugnar la legalidad de aquellas resoluciones judiciales que han privado de libertad a una persona, a saber:

1.- Los medios procesales que correspondan ante el tribunal que la hubiere dictado ${ }^{25}$,

24 En el mismo sentido, véase Aldunate, Enrique (2007) Panorama actual del amparo y Habeas Corpus en Chile, en Estudios Constitucionales, Año $5 \mathrm{~N}^{\circ} 1$, Universidad de Talca, pp., 18-29, p. 26. Cerda, Rodrigo (2010) Manual del Sistema de Justicia Penal, Tomo I, Segunda edición. Santiago: Librotecnia, 438 pp., p. 359. En un sentido similar, Hadwa, Marcelo (2015) La prisión preventiva y otras medidas cautelares personales. Santiago: Editorial Jurídica de Chile, 331 pp., pp. 200 y 201.

25 En el caso de la medida cautelar personal de detención, la impugnación de su legalidad se realiza, por regla general, ante el Juez de Garantía en la audiencia de control de la detención, incidentando la ilegalidad de la misma. Aquí puede encontrarse una de las razones principales del poco uso práctico del amparo ante el Juez de Garantía, por cuanto la audiencia de control de la detención termina subsumiendo las potenciales discusiones que pudieron plantearse en sede de amparo. En este sentido, Nieva (2012) 181. Por su parte, la resolución que dicta el tribunal declarando la legalidad de la detención -rechazando en consecuencia la incidencia de la defensa- es inimpugnable. Respecto de la prisión preventiva y de las medidas cautelares personales del artículo 155 del Código Procesal Penal, se contempla a su respecto la procedencia del recurso de apelación como mecanismo de impugnación. También se puede citar el rol del recurso de reposición, respecto de aquellas decisiones adoptadas en audiencia por un tribunal con competencia en materia penal, en las que no haya precedido debate a la decisión que implique una afectación a la libertad personal y seguridad individual o bien de aquellas dictadas fuera de audiencia, uno y otro caso, se darían por ejemplo con la dictación de órdenes de detención basadas en el artículo 127 del Código Procesal Penal. En este mismo sentido, Núnez indica que "si la privación de libertad hubiere sido ordenada por resolución judicial, como serían las detenciones y órdenes de prisión emanadas de los jueces de garantía y tribunales orales en lo penal, o los arrestos decretados por los juzgados civiles, de menores o del trabajo -según lo establece el inciso final del artículo 95 del C.P.P., antes transcripto-, su ilegalidad e improcedencia y la correspondiente solicitud de libertad deberá impetrarse al mismo tribunal que la dictó por la vía de la reposición, o ante las Cortes de Apelaciones respectivas por la vía de la acción de amparo constitucional", NúŃEZ, J.C. (2003) 388. 


\section{2.- El amparo del artículo 21 de la Constitución Política de la Repú- blica.}

Una simple lectura de este inciso final del artículo 95 del Código Procesal Penal, podría llevarnos a sostener que el amparo ante el Juez de Garantía allí previsto no procedería respecto de resoluciones judiciales, por cuanto el propio legislador lo ha dejado establecido en dicho inciso, al indicar que existe esta doble vía constituida por los medios de impugnación generales ante el tribunal que dicta la resolución y el amparo constitucio$\mathrm{nal}^{26}$. Tal es por ejemplo la posición de parte de nuestra doctrina, que señala al efecto que "la ley excluye expresamente la competencia del referido juez unipersonal para pronunciarse sobre las privaciones de libertad ordenadas por resolución judicial, las cuales solo pueden ser impugnadas por los medios procesales que correspondan ante el tribunal que las hubiere dictado, sin perjuicio de lo establecido en el artículo 21 de la Constitución Política de la República" 27 . Con esta postura se pasan absolutamente por alto las diversas finalidades que están asociadas al amparo legal, y que van mucho más allá de la discusión de legalidad en los términos del inciso tercero, por lo que quienes sostienen esta visión concluyen que "esta

26 Se utiliza este inciso tercero, y la doble vía que allí destacamos, como un argumento a favor de la procedencia del habeas corpus del artículo 21 de la Constitución en contra de resoluciones judiciales, conclusión que no es del todo pacífica, por cuanto a nivel doctrinario y jurisprudencial existen y han existido pronunciamientos donde derechamente se ha declarado que la acción constitucional de amparo es improcedente para atacar resoluciones judiciales. En nuestra doctrina, Mosquera y Maturana (2013) 438 y 439, quienes en apoyo de sus tesis citan a Tavolari. A nivel jurisprudencial podemos citar SCA de Santiago Rol N ${ }^{\circ} 2771$ 2010, de 28 de septiembre de 2010, dictada por los Ministros Sr. Dahm y Sra. Melo, y el Abogado Integrante Sr. Cruchaga, que en lo pertinente resolvió "que los fundamentos del recurso, no corresponden a aquellos que según el art. 21 CPR hacen admisible una acción de su especie, toda vez que esta no es la vía para impugnar resoluciones judiciales, por lo cual la deducida no puede ser acogida a tramitación". Dicha resolución fue revocada por SCS Rol N ${ }^{\circ} 7385-2010$, de 7 de octubre de 2010, disponiéndose por el máximo tribunal "que de conformidad a lo dispuesto en el inciso final art. 95 CPP, la acción de amparo constitucional es compatible con los otros medios de impugnación de una resolución judicial, razón por la cual no es motivo para declarar la inadmisibilidad de un recurso de amparo, el hecho que se haya dirigido contra una decisión jurisdiccional". En el mismo sentido de este último criterio sostenido por la Corte Suprema, y que es por cierto la tesis a la cual adherimos, véase también SCS Rol N 6720-2010, de 10 de septiembre de 2010, citada por HeNRíQUEZ, Miriam (2013) “¿Hacia una ampliación del habeas corpus por la Corte Suprema?”. Revista de Derecho Universidad Católica del Norte, Año 20 No 2, pp. 421-437, p. 422. En doctrina comparada, López-Muñoz y Larraz, Gustavo (1992) El auténtico habeas corpus. Madrid: Colex, 114 pp., p. 55 y ss. Carrió, Alejandro (2012) Garantías constitucionales en el proceso penal, 5 a edición. Buenos Aires: Hammurabi, 750 pp., p. 200 y ss. SAGües, Pedro (2008) Habeas Corpus, 4a edición. Buenos Aires: Astrea, 565 pp., pp. 161 y ss.

27 NúNEz (2003) 384. "En esta sede jurisdiccional son impugnables por la vía del amparo únicamente los actos de los particulares o de las autoridades administrativas que importen, en sentido amplio, "privación arbitraria y efectiva de la libertad", es decir, cuando esta sea expedida en los casos no autorizados por la ley". NúŃEz (2003) 387. En el mismo sentido, Chahuán (2012) 128 y 129, Castro (2008) 566. Correa, Jorge (2005) Recursos Procesales Penales. Santiago: LexisNexis, 404 pp., p. 360. Maturana y Montero (2012) 670. 
especie de amparo legal nunca podrá interponerse ante el juez de garantía o tribunal oral en lo penal que haya decretado la privación de libertad y simultáneamente conozca del caso, ya que en tal eventualidad ante este solo procedería la reposición o la acción habeas corpus ante la Corte de Apelaciones respectiva, contemplada en el artículo 21 de la Constitución Política, según lo dispone el inciso final del precitado artículo 95 del C.P.P.”28.

De acuerdo a lo que hemos venido sosteniendo, y a la clara diferenciación de finalidades que pueden estar asociadas al ejercicio del amparo del artículo 95, la respuesta a la pregunta de si dicho amparo procede o no en contra de resoluciones judiciales que han privado de libertad a alguna persona, creemos que admite una segunda lectura. Los propios incisos primero y segundo del artículo 95 del Código Procesal Penal se encargan de dejar de manifiesto que las finalidades que persigue el amparo allí regulado van mucho más allá de la discusión de legalidad que puede estar asociada a una privación de libertad, por cuanto es perfectamente posible accionar por esta vía solicitando que el juez se apersone en el lugar donde se encuentra la persona privada de libertad o bien que esta sea conducida a su presencia, para efectos de examinar las condiciones bajo las cuales está, y/o adoptar medidas pertinentes para resguardar los derechos que puedan estar siendo afectados y que nazcan de esta privación de libertad, entre otras medidas, tal como genéricamente concluye la norma en estudio ${ }^{29}$.

Si nos situamos en los márgenes del inciso tercero, esto es, que la privación de libertad haya emanado de una resolución judicial, su legalidad, y solo esa finalidad, podrá ser impugnada en la manera allí establecida, esto es, con la doble vía constituida por los medios de impugnación que contempla la legislación para ante el propio tribunal que la dictó, y a todo evento, pudiendo ejercer siempre la acción de amparo constitucional del artículo 21 de la Constitución Política de la República ${ }^{30}$. Esto quiere

\footnotetext{
28 NúŃEZ (2003) 389.
}

29 En este punto seguimos lo sostenido por Fernández, y que en lo relativo a la diversificación de las finalidades del amparo legal manifiesta que "de esta manera, cuando la privación de la libertad personal ha sido ordenada por un juez, el amparo legal no puede tener por finalidad impugnar su legalidad, sino cualquiera de los otros objetivos estipulados en el artículo 95, esto es, que el afectado sea conducido ante el juez; que este examine las condiciones en que aquel se encuentra, constituyéndose en el lugar, de ser necesario; que se ordene su libertad; o que el juez adopte las medidas que estime procedentes. En consecuencia, el amparo legal queda circunscrito para impugnar privaciones de libertad y en el caso que la decisión provenga de un juez no puede usarse como medio para impugnar su legalidad. Con ello, asimismo, queda en evidencia que el amparo legal resulta procedente no solo en contra de resoluciones judiciales, sino que también respecto de decisiones de otras autoridades siempre que estas hayan privado de la libertad personal al afectado". Fernández, Miguel Ángel (2003) Cuestiones constitucionales en torno del Código Procesal Penal. Biblioteca Fiscalía Nacional. Santiago: inédito, p. 49. En el mismo sentido, Fernández (2006) 43.

30 Sobre hipótesis de amparos en contra de resoluciones judiciales, véase, Verdugo, Mario (2014) "El habeas corpus en los tribunales". Revista de Derecho. Derechos y Garantias, Universidad Finis Terrae, Segunda época, año II, Nº 1-2014, pp. 195-213. 
decir, que si lo que se busca a través del ejercicio de la acción de amparo del artículo 95 del Código Procesal Penal es algo diverso al examen de legalidad (recuérdese las otras finalidades que contempla el legislador) esta acción legal será perfectamente procedente en hipótesis en que la privación de libertad haya surgido como consecuencia de una resolución judicial. Con ello se rompe este aparente absolutismo de la norma que haría inaplicable el amparo del artículo 95 ante resoluciones judiciales que han privado de libertad a personas determinadas. Claramente la respuesta negativa va a ser acertada cuando se persiga cuestionar la legalidad de dicha resolución, pero no será sostenible cuando la finalidad que se persiga con dicho amparo sea una diversa al test de legalidad ya referido, por cuanto en este último caso se tornan completamente aplicables los alcances de los incisos primero y segundo del artículo 95 del Código Procesal Penal ${ }^{31}$.

\section{4) Procedencia del amparo legal ante resoluciones dictadas POR JUECES CON COMPETENCIA DIVERSA A MATERIA PENAL}

Asumiendo una amplitud en la procedencia de la acción de amparo legal del artículo 95, surge de inmediato una segunda interrogante, ¿es aplicable el amparo del artículo 95 del Código Procesal Penal a privaciones de libertad que provengan de resoluciones que hayan emanado de jueces con competencia diversa a la criminal?, esto es, ¿es posible accionar de amparo legal ante resoluciones dictadas por jueces con competencia civil, laboral, policía local, etcétera?

Esta interrogante ha sido asumida por el Fiscal Nacional del Ministerio Público, quien mediante el Oficio No 60 ya citado, ha establecido una postura restringida a la hora de dar una respuesta a esta pregunta. Así, sostiene que los juzgados de garantía están circunscritos en su rol solamente al proceso penal, no teniendo competencia alguna para conocer de amparos "no penales", por cuanto para conocer de tales materias ya existen magistraturas avocadas a ello, como lo son, las Cortes de Apelaciones y la Corte Suprema, al conocer de la acción de amparo constitucional y

31 En una posición diversa, puede consultarse lo seńalado por Beca, quien al explayarse sobre la procedencia del amparo legal en contra de resoluciones judiciales, señala que "este amparo será aplicable en los casos en que una persona sea arrestada o detenida sin una orden judicial previa (por ejemplo, por orden de autoridad administrativa o al ser sorprendida en delito flagrante), o cuando por cualquier otro motivo se hallare privada de libertad, sea esta privación atribuible a autoridades públicas o a particulares [...] Tampoco es competente este tribunal (el juzgado de garantía), como ya se dijera, en el caso de existir una orden judicial que ordene la privación de libertad". BECA, Juan Pablo (2001) "El amparo ante la reforma procesal penal". Revista de Derecho de la Universidad Católica de Valparaiso, XXII, pp. 215255 , p. 253. 
del recurso de apelación que recae sobre la resolución que se pronuncia sobre ella, respectivamente.

Esta tesis, que como hemos dicho puede catalogarse de restrictiva, hace una distinción entre amparos "penales" y "no penales". Por regla general, solo los amparos "penales" serían de competencia de los juzgados de garantía, por cuanto son materias que estarían vinculadas directamente con sus funciones dentro del proceso penal, en cambio los amparos "no penales", entendiendo por tales todos aquellos amparos que puedan surgir como consecuencia de alguna actuación de un órgano jurisdiccional ajeno a materia penal, van a ser de competencia exclusiva del amparo constitucional del artículo 21 .

Sostiene además, que el inciso $3^{\circ}$ del artículo 95 obliga a reclamar ante el propio tribunal que ordenó la privación de libertad, supuesto que no se daría con un reclamo al Juzgado de Garantía en contra de la detención decretada por ejemplo, por un juez civil, del trabajo, entre otros ${ }^{32}$.

En ese orden de ideas, en términos prácticos la tesis en comento apunta a que cada vez que una persona detenida recurra ante el Juez de Garantía, y en su petición se excedan las finalidades propias del amparo legal del artículo 95 (reclamar de su detención o de las condiciones de esta), o bien se impetren peticiones propias de un amparo "no penal", deberá solicitarse la incompetencia de dicho tribunal, por cuanto aquella petición le compete a la magistratura establecida en el Código Orgánico de Tribunales, esto es, la Corte de Apelaciones respectiva ${ }^{33}$.

Como respuesta a esta tesis restringida, surge una alternativa que asume de manera afirmativa la interrogante en torno a la procedencia del amparo del artículo 95 del Código Procesal Penal ante resoluciones judiciales emanadas de jueces con competencia diversa a la penal. Así, Aldunate defiende esta tesis amplia que enarbola como su principal argumento

32 De lo anterior, podría sostenerse que las alternativas no comprendidas en artículo 95 del Código Procesal Penal deberían quedar incluidas en el artículo 21 de la Constitución y que, en cambio, la situación prevista en artículo 95 estaría entregada exclusivamente al juzgado que estuviere conociendo del caso o al que corresponda al lugar donde se encuentre el detenido. Ante lo cual, el Fiscal Nacional indica que incluso aquellas detenciones contra las cuales es procedente el amparo del artículo 95, están y siguen estando amparadas por el artículo 21 de la Constitución, y pueden dirigirse ante la Corte de Apelaciones, que es la magistratura correspondiente, conforme lo establecen los artículos 21 de la Carta Fundamental y 63 del Código Orgánico de Tribunales, de modo que no es correcto sostener que el juez de garantía tiene facultad exclusiva de conocer del amparo previsto en artículo 95 del Código Procesal Penal, Ministerio Público (2014) 48.

33 Agrega el Fiscal Nacional, que en el caso del amparo especial del artículo 95 del Código Procesal Penal, los fiscales deben ser oídos por el juez de garantía antes de resolver el reclamo, por lo que debe rechazarse un procedimiento unilateral en que solo se escuche al imputado. Y si el juez de garantía acoge la reclamación anterior, su resolución será apelable o no, según si se configuren las causales de apelación del artículo 370 del Código Procesal Penal, es decir, si ello no ocurre la resolución del juez será inapelable, Ministerio Público (2014) 50 . 
la facilitación al acceso a tutela judicial en casos de privaciones de libertad que puedan ser subsumidos en los márgenes de la acción de amparo legal, y que hayan sido consecuencia de resoluciones judiciales, sea cual sea la competencia del tribunal que la haya dictado ${ }^{34}$.

Compartimos totalmente esta segunda forma de enfrentar este problema interpretativo, por cuanto entendemos que el legislador ha buscado con el establecimiento de una acción de amparo a nivel legal, facilitar el acceso de los ciudadanos que se encuentren en hipótesis como las allí previstas, y poder requerir la tutela de los tribunales para que estos puedan velar de una manera rápida y expedita, por el respeto de sus derechos, en particular, el derecho a la libertad personal y seguridad individual.

Junto con este primer argumento, debemos recordar lo que ya hemos venido seńalando en torno a la pluralidad de objetivos que pueden perseguirse mediante la acción de amparo del artículo 95 del Código Procesal Penal, siendo el examen de legalidad una de dichas finalidades, mas no la única. En este sentido, tal como seńala el inciso final del artículo 95, "si la privación de libertad hubiere sido ordenada por resolución judicial, su legalidad solo podrá impugnarse por los medios procesales que correspondan ante el tribunal que la hubiere dictado, sin perjuicio de lo establecido en el artículo 21 de la Constitución Política de la República", cuando lo que se busque impugnar a través de esta acción de amparo sea la legalidad de la resolución judicial que dispuso la privación de libertad, indefectiblemente deberemos ceñirnos al tenor manifiesto del inciso en comento, esto es, recurrir a los mecanismos de impugnación contemplados en la ley para ante el propio tribunal que dictó dicha resolución, o bien, en todo caso, optar por la vía constitucional de la acción de amparo del artículo 21 de la Constitución. Pero si lo que se persigue con la acción de amparo del artículo 95 es diverso a la impugnación de la legalidad de una resolución que ha privado de libertad a una persona, es perfectamente posible utilizar dicho mecanismo correctivo ante privaciones de libertad que han emanado de resoluciones judiciales cuando se persigan las otras finalidades contempladas en el artículo 95. En este punto debe darse un énfasis a la respuesta, en el sentido que la competencia del Juez de Garantía es perfectamente comprensiva de privaciones de libertad que emanen de resoluciones judiciales de jueces con competencias diversas a la penal, en la medida que lo que se pretenda impugnar a través de esta acción sea algo diverso de la revisión de la legalidad de dicha resolución. Tales objetivos pueden ser, que el afectado sea conducido ante el juez, que el juez examine condiciones bajo las que se encuentra dicha persona privada de libertad, que el juez se constituya en el lugar de privación de libertad, que el juez adopte las medidas pertinentes para resguardar el respeto de los

Aldunate (2007) 18-29. 
derechos de la persona que acciona de amparo, y por supuesto, examinar la legalidad de la privación de libertad, cuando esta ha emanado de un organismo o persona que no ejerza jurisdicción, esto es, de una privación de libertad que no ha tenido su génesis en una resolución judicial.

Con esta manera amplia de entender el asunto planteado, se satisface plenamente lo que el legislador ha buscado con la institución del amparo, y que no es otra cosa que facilitar el acceso a la tutela judicial de quienes vean sus derechos afectados en este ámbito. Para ello baste constatar la ubicación geográfica y número de Cortes de Apelaciones (tribunal competente para conocer en primera instancia de los recursos de amparo constitucionales) y los Juzgados de Garantía a lo largo del país ${ }^{35}$.

A mayor abundamiento, hay que constatar además, que el inciso final del artículo 95 cuando se refiere a la privación de libertad ordenada por resolución judicial, no hace especificación alguna respecto del origen de la misma, esto eso, no circunscribe dichas resoluciones solo a tribunales con competencia en materia penal, sino por el contrario hace una referencia genérica a la resolución judicial dictada, no distinguiendo el tribunal del cual procede, por lo que constituye un punto adicional para fortalecer la tesis amplia que venimos detallando y defendiendo.

\section{5) Procedencia del amparo legal ante privaciones de LIBERTAD QUE EMANEN DE AUTORIDADES QUE NO EJERZAN JURISDICCIÓN}

¿Qué pasa con aquellas privaciones de libertad que emanan de autoridades que no ejerzan jurisdicción? En este punto el Oficio $N^{\circ} 60 / 2014$ que hemos mencionado anteriormente, sostiene que tampoco quedan cubiertas bajo el alcance del artículo 95 del Código Procesal Penal aquellas privaciones a la libertad personal que puedan sufrir los individuos por autoridades administrativas (por ejemplo, arrestos), siempre que estén fuera o sean ajenas al proceso penal. Se haría con ello una especie de distinción

35 Un ejemplo claro de ello es la propia Región Metropolitana, la cual cuenta con dos Cortes de Apelaciones, la de Santiago y San Miguel, por lo que algún habitante de la comuna de Colina que estuviese bajo alguna de las hipótesis del artículo 95 del Código Procesal Penal, cuya privación de libertad hubiese emanado de una resolución judicial de un juez con competencia distinta a la penal, y desease por ejemplo que se verificaren las condiciones bajo las cuales se encuentra privado de libertad, de sostener la tesis restringida, deberíamos entender que si desea accionar de amparo solo tendría la vía constitucional para ante la Corte de Apelaciones respectiva, en este caso, la Corte de Apelaciones de Santiago. En cambio, al sostener la tesis amplia aquí defendida, dicha persona podría perfectamente accionar ante el Juzgado de Garantía de Colina, que correspondería al tribunal del lugar donde se encuentra privada de libertad, teniendo siempre a salvo, la posibilidad de optar por la acción constitucional, si así lo desease. 
en cuanto a si la decisión administrativa estaría o no vinculada al proceso penal, para efectos de determinar la competencia del tribunal a la hora de conocer de este amparo legal. Nosotros entendemos que es perfectamente aplicable el amparo del artículo 95 del Código Procesal Penal a esas hipótesis de privación de libertad, por cuanto no existirá la limitante del inciso tercero en términos de excluir la legalidad como objeto de discusión en la acción de amparo del artículo 95 cuando emane la privación de libertad de una resolución judicial, lo que nos reconduce a la regla general de aplicación del artículo 95: cuando una persona privada de libertad requiera que un tribunal examine la legalidad de dicha decisión o bien cualquiera de las otras finalidades de la norma aludida. El aforismo de "quien puede lo más, puede lo menos" resulta ilustrativo en este punto, por cuanto si es posible accionar de amparo legal ante resoluciones judiciales cuando no se discuta su legalidad, sea cual sea la competencia de dicho tribunal, con mayor razón se va a poder utilizar esta acción del artículo 95 del Código Procesal Penal cuando la privación de libertad haya emanado de la decisión de alguna autoridad que no ejerza jurisdicción. El "juez de garantía es competente para conocer y pronunciarse sobre los amparos interpuestos en contra de los arrestos o detenciones ordenados por las autoridades administrativas, cualquiera que sea la naturaleza de estas y el fundamento gubernativo o penal que haya motivado la privación de libertad, ya que el inciso primero del artículo 95 del C.P.P. no distingue al respecto, y, además, la Comisión de Constitución, Legislación, Justicia y Reglamento del Senado, en su Sesión 5a, antes inserta, al referirse a la materia, al igual que en el texto de la ley, aludió, en general, a que la "acción de amparo ante el juez de garantía apunta en contra de las acciones de la autoridad que afecten la libertad" 36 . Con ello, se logra una coherencia con lo manifestado en el punto anterior, en el sentido que lo relevante es poner el énfasis en la afectación producida a aquel que se encuentra privado de libertad, independiente cuál sea la génesis de la misma: órgano que ejerza jurisdicción o no.

En materia penal, dentro de las autoridades que no ejercen jurisdicción, podemos citar los casos de actuaciones realizadas por la policía sin orden judicial, incluso sin instrucción de los fiscales del Ministerio Público en ejercicio de sus facultades autónomas, que los habilitan a detener en hipótesis de flagrancia ${ }^{37}$, lo cual se extiende a los particulares que también pueden actuar justificadamente deteniendo en flagrancia, de acuerdo a la normativa actualmente vigente en materia procesal penal ${ }^{38}$, o como destaca Carocca, cuando "el detenido es puesto a disposición del fiscal, quien

NúNÉz (2003) 388.

Artículos 83, 85, 129, 130 y 131 del Código Procesal Penal.

En este sentido, véase Piedrabuena, Guillermo (1999) El Recurso de Apelación y la Consulta.

Santiago: Editorial Jurídica de Chile, 468 pp., p. 385. 
debe resolver en el plazo de 24 horas si lo pone en libertad, solicita al juez de garantía la prolongación de la detención hasta por otros tres días [...] En el evento que no adopte oportunamente ninguna de estas decisiones, incurrirá en detención ilegal y procederá incluso el habeas corpus o amparo ante el juez de garantía [...]"39. Otro tanto ocurre a nivel de decisiones administrativas que se adoptan en materias migratorias, y que en lo concreto implican privaciones de libertad ${ }^{40}$.

\section{CONCLUSIONES}

1. La "acción de amparo ante el Juez de Garantía" ha sido interpretada en cuanto a sus alcances de manera restrictiva, dejando fuera de su ámbito de aplicación a aquellas privaciones de libertad que emanan de resoluciones judiciales (tanto de tribunales con competencia en materia penal como aquellos de competencia diversa), así como también respecto de aquellas hipótesis que tienen su génesis en decisiones de autoridades que no ejerzan jurisdicción.

2. Junto con lo anterior, no ha habido claridad con relación al tribunal competente para conocer sobre esta acción cautelar de rango legal, concluyendo parte de nuestra doctrina que serían potencialmente competentes en esta materia los Tribunales de Juicio Oral en lo Penal, en la medida que nos encontremos en la tercera etapa del proceso penal.

3. Existe una baja utilización práctica de esta acción de amparo, esencialmente atribuible a la superposición que se origina con la discusión propia de la audiencia de control de la detención, en la cual se resuelve acerca de la legalidad de la detención a que ha sido sometida un imputado (plazo de 24 horas para ponerlo a disposición del tribunal).

4. Puede constatarse del propio tenor del artículo 95 del Código Procesal Penal que las finalidades que pueden perseguirse a través de dicha acción exceden con creces a la discusión asociada a la legalidad de la privación de libertad, por cuanto es perfectamente posible solicitar al

39 Carocca, Álex (2009) Manual El Nuevo Sistema Procesal Penal Chileno, $5^{\text {a }}$ edición. Santiago: Thomson Reuters, 197 pp., p. 106. Estas detenciones provenientes de autoridades que no ejerzan jurisdicción han sido esencialmente sometidas a discusión en la audiencia de control de la detención, lo que explica en gran medida la baja utilización del amparo del artículo 95 en comparación con dicha audiencia.

40 A nivel práctico, lo vinculado a decisiones administrativas en materia de migración ha dado lugar a la interposición de acciones de amparo ante las Cortes de Apelaciones respectivas. Ello no obsta la procedencia de la acción del artículo 95 del Código Procesal Penal, en la medida que nos encontremos ante una privación de libertad, que como sabemos, es una hipótesis común tanto para el amparo legal como el habeas corpus constitucional. 
juez que examine las condiciones en que se encontrare la persona privada de libertad, constituyéndose, si fuere necesario, en el lugar en que ella estuviere. Podrá solicitarse al juez que ordene que la persona privada de libertad sea conducida a su presencia para que, en definitiva, el juez determine ordenar la libertad del afectado o bien adopte las medidas que fueren procedentes.

5. Luego, lo que el inciso tercero de la norma en comento refiere es que el test de legalidad que se pretenda realizar respecto de una resolución judicial que ha decretado una privación de libertad, excede los márgenes propios del Amparo ante el Juez de Garantía, dejando a salvo -como medios de impugnación de este tipo de resoluciones- la doble vía constituida por los medios procesales que correspondan ante el tribunal que la hubiera dictado, y a todo evento, el amparo constitucional del artículo 21 de la Constitución Política de la República.

6. Siempre será competente materialmente para conocer la acción de amparo del artículo 95 el Juez de Garantía, ya sea el que conociere del caso o aquel del lugar donde la persona privada de libertad se encontrare. Razones de texto, basadas en el propio tenor del artículo 95, y en lo dispuesto en el artículo 69 del Código Procesal Penal, en torno a la voz "juez", así como argumentos basados en la historia fidedigna del establecimiento de la ley, permiten descartar cualquier pretensión en orden a dotar de competencia en esta materia a los Tribunales de Juicio Oral en lo Penal.

7. El amparo del artículo 95 debe entenderse aplicable a hipótesis no solamente "penales" -como se ha pretendido-, sino que debe abarcar toda privación de libertad, ya sea que emane de cualquier autoridad o bien provenga de conductas desplegadas por particulares. Si emana de una resolución judicial, el ámbito de competencia de la acción de amparo legal abarca tanto los pronunciamientos de tribunales con competencia en materia penal como de aquellos con competencia en materias ajenas a lo penal, siendo solamente inaplicable respecto de aquellas hipótesis que buscan impugnar la legalidad de una resolución judicial que ha decretado una privación de libertad.

\section{BIBLIOGRAFÍA}

Aldunate, Enrique (2007) "Panorama actual del amparo y Habeas Corpus en Chile". Estudios Constitucionales, Año 5, No 1 .

BeCA, Juan Pablo (2001) "El amparo ante la reforma procesal penal". Revista de Derecho de la Universidad Católica de Valparaíso, XXII. 
Caffarena de Jiles, Elena (1957) El recurso de amparo frente a los regimenes de emergencia. Santiago: Imprenta San Francisco.

Carocca, Álex (2009) Manual El Nuevo Sistema Procesal Penal Chileno, 5ª edición. Santiago: Thomson Reuters.

CArrió, Alejandro (2012) Garantías constitucionales en el proceso penal, 5a edición. Buenos Aires: Hammurabi.

Castro, Javier (2008) Introducción al Derecho Procesal Penal Chileno, 2a edición. Santiago: LegalPublishing.

Cerda, Rodrigo et al. (2003) El Código Procesal Penal. Comentarios, concordancias y jurisprudencia. Santiago: Librotecnia.

Cerda, Rodrigo (2010) Manual del Sistema de Justicia Penal, Tomo I, 2a edición, Santiago, Librotecnia.

Chahuán, Sabas (2012) Manual del Nuevo Procedimiento Penal, 7a edición. Santiago: Thomson Reuters.

Correa, Jorge (2005) Recursos Procesales Penales. Santiago: LexisNexis.

De Diego, Luis (2011) Habeas corpus frente a detenciones ilegales, 2a edición. España: Bosch.

Durán, Rodrigo (2011) Medidas cautelares personales en el proceso penal, $3^{\text {a }}$ edición Santiago: Librotecnia.

Fernández, Miguel Angel (2003) Cuestiones constitucionales en torno del Código Procesal Penal. Biblioteca de la Fiscalía Nacional. Santiago: inédito.

Fernández, Miguel Ángel (2006) La nueva justicia penal frente a la Constitución. Santiago: LegalPublishing.

Flores, Rubén (2011) Amparo, habeas corpus y habeas data, $3^{\text {a }}$ edición. Buenos Aires: Editorial B de F.

Gude, Ana (2008) El habeas corpus en España. Valencia: Tirant lo Blanch.

Hadwa, Marcelo (2015) La prisión preventiva y otras medidas cautelares personales. Santiago: Editorial Jurídica de Chile

Henríquez, Miriam (2013) “¿Hacia una ampliación del habeas corpus por la Corte Suprema?”. Revista de Derecho Universidad Católica del Norte, Año 20, No 2.

Henríquez, Miriam (2014) "Habeas corpus". En Silva. M. y Henríquez, M. (coords.): Acciones protectoras de derechos fundamentales. Santiago: Thomson Reuters.

Horvitz, María Inés; y López, Julián (2003) Derecho Procesal Penal Chileno, Tomo I. Santiago: Editorial Jurídica de Chile.

Londoño, Fernando et al. (2003) Reforma procesal Penal. Génesis, historia sistematizada y concordancias. Tomo I, Código Procesal Penal Libro I. Santiago: Editorial Jurídica de Chile.

López-Muñoz y Larraz, Gustavo (1992) El auténtico habeas corpus. Madrid: Colex. 
Maturana, Cristián y Montero, Raúl (2012) Derecho Procesal Penal, Tomo I, 2a edición. Santiago: Editorial Jurídica de Chile.

Ministerio Público. Fiscalía Nacional (2014) Oficio $\mathrm{N}^{\circ}$ 60, Instrucción general que imparte criterios de actuación aplicables a la etapa de investigación en el proceso penal. Santiago: inédito.

Mosquera, Mario y Maturana, Cristián (2013) Los Recursos Procesales. Santiago: Editorial Jurídica de Chile.

Nieva, Jordi (2012) Fundamentos de Derecho Procesal Penal. Buenos Aires: Editorial B de F.

Nogueira, Humberto (2013) Derechos Fundamentales y garantías constitucionales, $4^{a}$ edición, Tomo 1 . Santiago: Librotecnia.

NúNEEz, Juan Cristóbal (2003) Tratado del proceso penal y del juicio oral, Tomo II. Santiago: Editorial Jurídica de Chile.

Núñez, Raúl (2016) Código Procesal Penal. Códigos Profesionales 2016. Santiago: Editorial Thomson Reuters-La Ley.

PÉrez, Alejandro (2008) Generalidades del habeas corpus constitucional chileno. Santiago: Librotecnia.

Pfeffer, Emilio (2010) Código Procesal Penal. Anotado y concordado. $3^{\mathrm{a}}$ Edición. Santiago: Editorial Jurídica de Chile.

Piedrabuena, Guillermo (1999) El Recurso de Apelación y la Consulta. Santiago: Editorial Jurídica de Chile.

SaGüEs, Pedro (2008) Habeas Corpus, 4a edición. Buenos Aires: Astrea.

Salas, Jaime (2015) Problemas del proceso penal. Investigación, etapa intermedia y procedimientos especiales, $2^{\mathrm{a}}$ edición. Santiago: Librotecnia.

Tavolari, Raúl (1995) Habeas Corpus. Recurso de amparo. Santiago: Editorial Jurídica de Chile.

Verdugo, Mario (2014) "El habeas corpus en los tribunales". Revista de Derecho. Derechos y Garantías, Universidad Finis Terrae, Segunda época, año II, $N^{\circ}$ 1-2014. 